\title{
Post-Fault Compensation Control Strategy for Multi-Three-Phase PMSM under Open-Circuit and Short-Circuit Condition
}

\author{
Azlia A. Rahman, A. Galassini, M. Degano, H. Abbas, S. Bozhko
}

\begin{abstract}
This paper presents two post-fault compensation strategies for the distributed current control of a ninephase Permanent-Magnet Synchronous Machine (PMSM). The dynamic performance in faulty condition is guaranteed by keeping the current loop bandwidths constant. The two faults under investigation are Open-Circuit (OC) and Short-Circuit (SC) of one set of the three-phase windings. The decoupled mathematical model of the machine in post-fault conditions are derived prior to the control strategies are designed. The Vector Space Decomposition (VSD) is used and the design for the controllers is revised. While short-circuiting one set of three-phase windings, in order to eliminate different electromagnetic interactions, different lag compensators for different healthy modules are introduced. The proposed post-fault control strategies are compared against the step response in nominal condition and further validated by means of Matlab/Simulink ${ }^{\circledR}$ simulations, where three Two-Level ThreePhase Voltage Source Inverters (2L-3P-VSIs) are used to supply the machine.
\end{abstract}

Index Terms-Multi-three phase machine, current control, fault tolerance

\section{INTRODUCTION}

FAULT-tolerant capability of electric motor drives is paramount importance in safety-critical applications such as aerospace and Electric Vehicle (EV). Since beginning of the 20th century, the multiphase machines (more than three-phase) have been investigated due to their advantages over conventional three-phase machines, such as lowering dc harmonics and increasing reliability [1]-[5]. Among multiphase machines, an innovative Multi-Three-Phase Machines (MTPM) are a particular subgroup, which the main advantage is the reuse of all the know-how regarding different control strategies, fault detection, fault isolation, and winding design for the unit block [6], [7]. They are obtained by winding multiphase machine phases into three-phase subwindings sets with isolated neutral points [6], [8]. Powertrain re-design with MTPM leads to modularity by extending redundancy from the power electronics to the control unit level [6]. More precisely, multiple Two-Level Three-Phase Voltage Source Inverters (2L-3P-VSIs), like the one shown in Fig. 1, are connected in parallel rather than in series to obtain a redundant system [6], as illustrated in Fig. 2.

One of the most acclaimed advantage of multiphase machines is their ability to operate under faulty conditions [7], [9]-[17]. However, the post-fault control of multiphase PM machine is a challenging task due to numerous fault scenarios which are depending on the number of phases, fault type (OC or SC), connection of stator windings, fault

Azlia A. Rahman, A. Galassini, and M. Degano are with the PEMC group, The University of Nottingham.

H. Abbas are with the Electrical and Electronic Department, University of Nottingham, Malaysia Campus.

S. Bozhko are with the Aircraft Electric Power Systems, Faculty of Engineering, University of Nottingham.

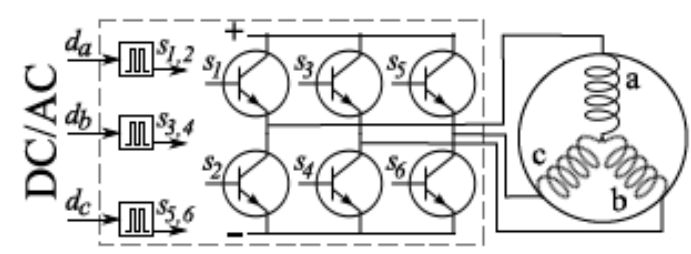

Fig. 1. Module of 2L-3P-VSI and one three-phase set of windings (a,b,c) [9].

location and etc. [12]. Therefore, an extensive research work has been recently done to keep constant the current control performance under fault conditions [7], [9], [11]-[18]. Faulttolerant operation under SC faults is more challenging especially for PM machines, where most of the reported works are limited considering one or some of the factors mentioned above and usually devoted to OC fault-tolerant control [10].

Based on the work presented in [7], this paper extends the analysis by adding the power electronics converters, shown in Fig. 1, feeding a nine-phase PMSM, Fig. 2 and by introducing a lag compensator for the SC condition. The distributed current control is presented in nominal (or healthy) and under faulty conditions, both in OC and SC. In order to guarantee optimal dynamic performance in all operating condition of the machine, different post-fault compensation strategies for keeping the current loop bandwidths constant are presented. Further validation is discussed using the VSD technique and Matlab/Simulink ${ }^{\circledR}$ simulations. After the introduction, the mathematical machine modelling in $d q 0$ reference frame [7] is presented in Sec. II. Details of current control design in nominal condition is detailed in Sec. III. The current control within the $d q 0$ reference frame and the VSD technique are compared, and their equivalence is revealed. In Sec. IV and Sec. V, fault-tolerant control strategies under OC and SC are presented and the lag compensator design is highlighted. In Sec. VI, the demonstrated post-fault control strategies are compared against the nominal condition and they are further validated by means of Matlab/Simulink ${ }^{\circledR}$ simulations. Finally, conclusions are discussed in Sec. VII.

\section{MATHEMATICAL MACHINE MODELLING}

In this section, the details of machine modelling technique is implemented based on analytical model in $d q 0$ reference frame. The considered modelling assumptions are according to the one demonstrated in [7], [9], where no restrictive assumption is made, instead, about whether the winding is distributed or concentrated and all the leakage flux components are considered. 


\section{A. Winding and power converter topology}

By defining $m$ as the number of phases per isolated set of windings (where $m=3$ for multi-three-phase system (phases a, b, and c in Fig. 1), $N$ is the number of windings sets, and the total number of phases is equal to $n=N m$. Therefore, the nine-phase machine is considered in this paper which is arranged in three-phase sets of windings ( $m=3$, $N=3, n=9$ ). The model is considered an asymmetrical split-phase scheme composed of $N$ symmetrical $m$ phase sections with odd number of phases $n=N m$ (Fig. 2 ). Hence, the phase progression in asymmetrical n-phase schemes is $\alpha=\pi / n$ [7], [9].



Fig. 2. Fully modular and redundant distributed current control diagram of a multi-three-phase machine with three sets of windings. [6].

According to Fig. 2, the considered configuration presents three sets of distributed converters, fully modular and redundant. There are two Proportional-Integral (PI) controllers per three-phase set and only the local three currents are provided as a feedback [6], [7].

\section{B. Analytical model in Park's transformation}

Based on an equivalent circuit of $\mathrm{d}$-axis and q-axis for PMSM, the whole set of machine variables can be thus transformed into $d q 0$ reference frame [7], [9]. Hence, the machine voltage equation in the new coordinate is:

$$
\begin{array}{r}
\mathbf{v}_{d q}=\mathbf{R}_{d q} \mathbf{i}_{d q}+\omega \mathbf{J} \mathbf{L}_{d q} \mathbf{i}_{d q}+\mathbf{L}_{d q} \frac{d \mathbf{i}_{d q}}{d t}+\mathbf{e}_{d q} \\
\text { with } \mathbf{v}_{d q}=\left[\mathbf{v}_{d q 1} \cdots \mathbf{v}_{d q N}\right]^{T}, \mathbf{i}_{d q}=\left[\mathbf{i}_{d q 1} \cdots \mathbf{i}_{d q N}\right]^{T} \\
\text { and } \mathbf{e}_{d q}=\left[\mathbf{e}_{d q 1} \cdots \mathbf{e}_{d q N}\right]^{T}
\end{array}
$$

where $\mathbf{v}_{d q}$ denotes the voltage, $\mathbf{i}_{d q}$ is the current, and $\mathbf{e}_{d q}$ is the back electromotive force vector $n x 1 . \mathbf{R}_{d q}$ and $\mathbf{L}_{d q}$ are respectively resistance and inductance matrices $n x n, \mathbf{J}$ is the $n x n j$ operator, $\theta$ is the rotor position, and $\omega=d \theta / d t$.

Distributed current control is achieved within the rotor orthogonal $d q 0$ (indicated as subscript $d q$ ) reference frame by applying the Park's transformation to the machine stator variables (denoted as subscript $a b c$ ) [7], [9]. Since the machine is a multi-three-phase system, the global Park's Transformation matrix is defined by the following equations:

$$
\mathbf{T}=\left(\begin{array}{ccc}
\mathbf{T}_{1} & \cdots & \mathbf{0}_{3} \\
\vdots & \ddots & \vdots \\
\mathbf{0}_{3} & \cdots & \mathbf{T}_{N}
\end{array}\right)_{n x n}
$$

$$
\begin{aligned}
& \mathbf{T}_{h}=\sqrt{\frac{2}{3}}\left(\begin{array}{ccc}
\cos [\theta-(h-1) \alpha] & \sin [\theta-(h-1) \alpha] & 0 \\
-\sin [\theta-(h-1) \alpha] & \cos [\theta-(h-1) \alpha] & 0 \\
0 & 0 & 1
\end{array}\right) \\
& \left(\begin{array}{ccc}
1 & -1 / 2 & -1 / 2 \\
0 & \sqrt{3} / 2 & -\sqrt{3} / 2 \\
1 / \sqrt{2} & 1 / \sqrt{2} & 1 / \sqrt{2}
\end{array}\right) \text { with } h=1 . . N
\end{aligned}
$$

where $\mathbf{0}_{3}$ is a $3 x 3$ null matrix [7].

Whilst $\mathbf{R}_{a b c}=\mathbf{R}_{d q}=r_{s} \mathbf{I}_{(n x n)}$ where $r_{s}$ is the stator phase resistance, the inductance matrix $\mathbf{L}_{d q}$ is obtained as follows:

$$
\begin{array}{r}
\mathbf{L}_{d q}=\left(\begin{array}{ccc}
\mathbf{L}_{d q(1,1)} & \cdots & \mathbf{L}_{d q(1, N)} \\
\vdots & \ddots & \vdots \\
\mathbf{L}_{d q(N, 1)} & \cdots & \mathbf{L}_{d q(N, N)}
\end{array}\right) \\
\text { with } \mathbf{L}_{d q(i, j)}=\mathbf{L}_{d q(j, i)}^{T}=\mathbf{T}_{h} \mathbf{L}_{a b c(i, j)} \mathbf{T}_{h}^{T}= \\
=\frac{3}{2}\left(\begin{array}{cccc}
L_{m d} & 0 & 0 \\
0 & L_{m q} & 0 \\
0 & 0 & 0
\end{array}\right)+\left(\begin{array}{ccc}
M_{i-j} & -X_{i-j} & 0 \\
X_{i-j} & M_{i-j} & 0 \\
0 & 0 & H_{i-j}
\end{array}\right)
\end{array}
$$

where $L_{m d}$ and $L_{m q}$ are denoted as $d, q$ auto inductances. Parameters $M_{k}, X_{k}, H_{k}$ are the stator leakage inductances expressed within the $d q 0$ reference frame. Their physical meaning can be found in [7] and [9].

In this case study, since $L_{m d}$ and $L_{m q}$ are the same, for the sake of brevity, only data regarding the q-axis from the first module will be presented.

\section{CURRENT CONTROL IN NOMINAL CONDITION}

This Sec. discusses the design of distributed current controllers in Nominal Condition (NC) achieved by diagonalising the inductance matrix by means of the VSD [7], [10], [11]. The design is based on the first harmonic inductance which is taking into account all the mutual interactions within the stator. Assuming the speed loop is not affecting the inner current control one, the current control loop design based on (1) can be done in locked rotor position. Hence, the mechanical speed $\omega$ is zero and Eq. (1) becomes:

$$
\mathbf{v}_{d q}=\mathbf{R}_{d q} \mathbf{i}_{d q}+\mathbf{L}_{d q} \frac{d \mathbf{i}_{d q}}{d t}
$$

Thanks to the VSD, decoupled links between each i-th input voltage and $\mathrm{j}$-th output current can be obtained. The transfer function matrices both in the $d q$ and $v s d$ space, are derived as follow:

$$
\mathbf{G}_{d q}=\mathbf{C}\left(s \mathbf{I}-\mathbf{A}_{d q}\right)^{-1} \mathbf{B}_{d q}+\mathbf{D}=\mathbf{Y}_{d q} / \mathbf{U}_{d q}
$$

where $\mathbf{A}_{d q}=-\mathbf{L}_{d q}^{-1} \mathbf{R}_{d q}, \mathbf{B}_{d q}=\mathbf{L}_{d q}^{-1}, \mathbf{C}, \mathbf{D}$, and $\mathbf{I}$ are respectively output, feed-through, and identity $n x n$ matrices, $\mathbf{U}_{d q}$ is the applied voltage input vector, and $\mathbf{Y}_{d q}$ is the output current vector; similarly, in the $v s d$ space:

$$
\mathbf{G}_{v s d}=\mathbf{C}\left(s \mathbf{I}-\mathbf{A}_{v s d}\right)^{-1} \mathbf{B}_{v s d}+\mathbf{D}=\mathbf{Y}_{v s d} / \mathbf{U}_{v s d}
$$

where

$$
\mathbf{L}_{v s d}=\mathbf{T}_{v s d}^{T} \mathbf{L}_{d q} \mathbf{T}_{v s d}
$$

In (8), the $\mathbf{T}_{v s d}$ matrix stands for the transformation matrix which maps the orthonormal coordinates $d q 0$ into the named vsd orthonormal space [7].

Being the $d q 0$ and the $v s d$ two orthonormal spaces, the two transfer function matrices represent in a different way in 


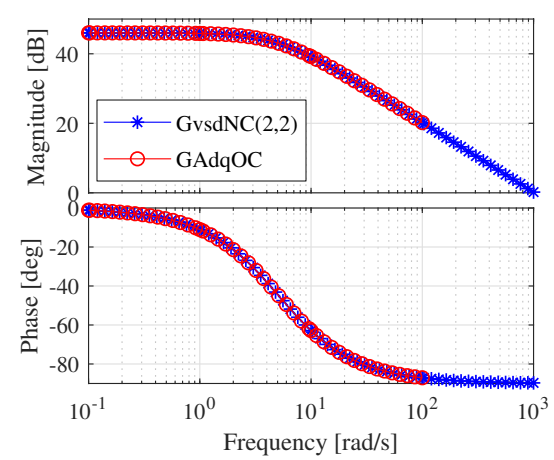

(a) Transfer functions in $\mathrm{NC}$ for $v s d$ and $d q 0$ state space models.

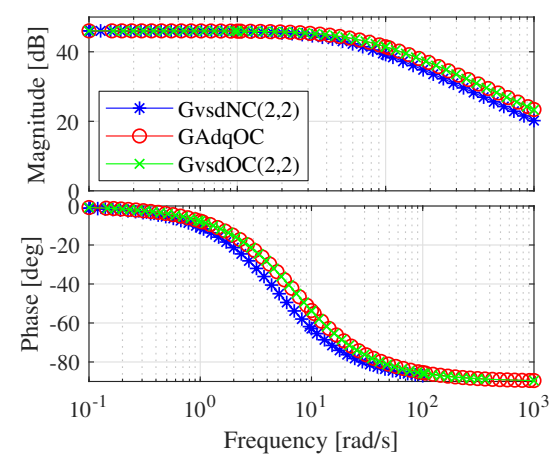

(b) Comparison between the dominant pole in $\mathrm{NC}$ and $\mathrm{OC}$.

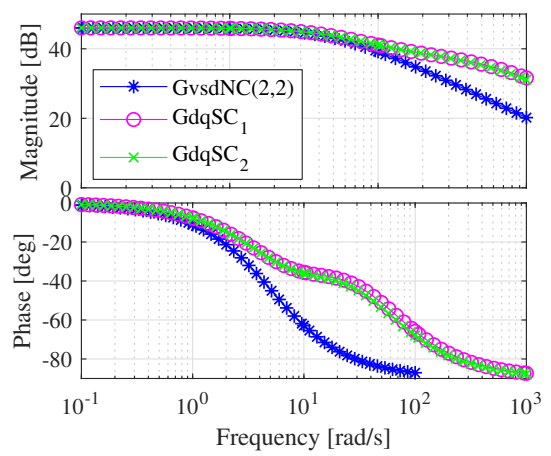

(c) The $q$ output current showing comparison between nominal and SC condition.

Fig. 3. Bode diagrams showing relationship in between NC, OC, and SC.

the same system [7], [19]. However, whilst $\mathbf{G}_{v s d}$ is diagonal, $\mathbf{G}_{d q}$ is not, like shown in (9).

$$
\mathbf{G}_{d q N C}=\left(\begin{array}{ccccccccc}
G & 0 & 0 & G & 0 & 0 & G & 0 & 0 \\
0 & G_{(2,2)} & 0 & 0 & G & 0 & 0 & G & 0 \\
0 & 0 & G & 0 & 0 & G & 0 & 0 & G \\
G & 0 & 0 & G & 0 & 0 & G & 0 & 0 \\
0 & G_{(5,2)} & 0 & 0 & G & 0 & 0 & G & 0 \\
0 & 0 & G & 0 & 0 & G & 0 & 0 & G \\
G & 0 & 0 & G & 0 & 0 & G & 0 & 0 \\
0 & G_{(8,2)} & 0 & 0 & G & 0 & 0 & G & 0 \\
0 & 0 & G & 0 & 0 & G & 0 & 0 & G
\end{array}\right)
$$

$\mathbf{G}_{v s d}$ and $\mathbf{G}_{d q}$ equivalence can be appreciated by comparing the transfer function linking the $d q$ input voltages to the $q$ output current of one set of winding, for example the first one, $\left(G_{A d q N C}=\sum_{k=1}^{n} G_{d q N C(k, 2)}\right)$ against the transfer function linking the first harmonic input voltage to the first harmonic output current along the $q$ axis, expressed by the following Eq.:

$$
G_{v s d N C(2,2)}=\frac{1}{s q_{1}+r_{s}}
$$

where $q_{1}$ is the first harmonic inductance along the $q$ axis. The Bode plots of the two transfer functions are plotted in Fig. 3a. $d q$ current controllers shown in Fig. 2 are then designed considering the plants $G_{v s d N C(1,1)}$ and $G_{v s d N C(2,2)}$ shown [7], [9]. In Fig. 4, the equivalent $q$ axis current control loop used to design the PI, is shown, where the Actuation Delay $A D(s)$ and a current Low-Pass Filter $L P F(s)$ have been introduced. More precisely, the blocks parameter in Fig. 4 are:

$$
\begin{gathered}
A D(s)=\frac{1}{s 1.5 T_{s}+1} \\
\operatorname{LPF}(s)=\frac{\omega_{f}^{2}}{s^{2}+\sqrt{2} \omega_{f} s+\omega_{f}^{2}}
\end{gathered}
$$



Fig. 4. Equivalent current control loop for NC design.

where $K_{P I N C}$ and $K_{i I N C}$ are respectively the updated proportional and integral PI gains parameter in $\mathrm{NC}, T_{s}$ is the interrupt time, $\omega_{f}$ stands for current filter cut-off frequency.

\section{FAULT-TOLERANT CURRENT CONTROL STRATEGY IN OPEN-CIRCUIT (OC)}

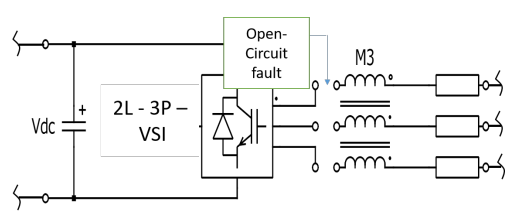

(a) The last set is disconnected.

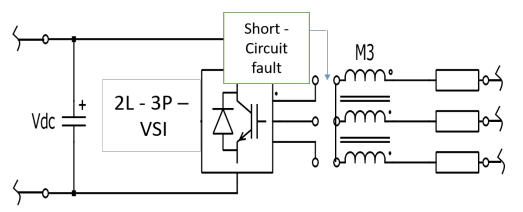

(b) The last set is in short circuit.

Fig. 5. Simulated faulty conditions.

In this section, the motor model developed in Sec. II with the last set of windings under OC fault condition is further investigated, Fig.5a. If in $\mathrm{NC}$ the number of phases is $n_{N C}=$ $N_{N C} m=9$, in OC condition the number of active phases is $n_{O C}=N_{O C} m=6$ being $N_{O C}$ equal to two instead of three. By deleting the last three rows and the last three columns from the $\mathrm{NC}$ matrices and the last three elements from the NC vectors, the OC transfer function matrix can be derived like in Sec. III.

$$
\begin{gathered}
\mathbf{G}_{d q O C}=\mathbf{C}_{d q O C}\left(s \mathbf{I}-\mathbf{A}_{d q O C}\right)^{-1} \mathbf{B}_{d q O C}+\mathbf{D}_{d q O C} \\
\mathbf{G}_{v s d O C}=\mathbf{C}_{v s d O C}\left(s \mathbf{I}-\mathbf{A}_{v s d O C}\right)^{-1} \mathbf{B}_{v s d O C}+\mathbf{D}_{v s d O C}
\end{gathered}
$$

The two equivalent transfer functions

$$
G_{A d q O C}=\sum_{k=1}^{n_{O C}} G_{d q O C(k, 2)} \text { and } G_{v s d O C(2,2)}
$$

are obtained considering the two reduced transfer function matrices in (13) and (14). Their Bode plots are shown in Fig. 3b, where it is possible to appreciate their equivalence. In the same Fig. 3b, the difference between the $\mathrm{NC}$ and the OC plants can be appreciated. Indeed, $G_{A d q O C(2,2)} \neq$ $G_{v s d N C(2,2)}$. By considering the first OC harmonic inductance $q_{1 O C}$, current dynamics in OC condition can be kept constant. Current controller in OC can be designed by considering the current loop in Fig. 6, where $K_{P I O C}$ and $K_{i I O C}$ are respectively the updated proportional and integral PI gains parameter in OC. 




Fig. 6. Equivalent current control loop design under OC fault condition.

\section{FAULT-TOLERANT CURRENT CONTROL IN SHORT-CIRCUIT (SC)}

Considering the model under SC fault condition in Fig. 5b, the $d q$ voltages of the third set of windings are zero $\left(v_{a 3}=\right.$ $v_{b 3}=v_{c 3}=0$ ). The current dynamics of the two healthy sets are affected by these SC currents circulating within the faulty set. In order to design the current controllers under SC fault condition while ensuring constant current dynamics, it is essential to derive the transfer functions linking the healthy $q$ input voltages $\left(v_{d q(2,1)}, v_{d q(5,1)}\right)$ to the healthy $q$ output currents $\left(i_{d q(2,1)}, i_{d q(5,1)}\right)$, where $n_{S C}=n_{N C}-3$.

$$
\begin{aligned}
& G_{d q S C 1}=G_{d q N C(2,2)}+G_{d q N C(5,2)}=\sum_{k=1}^{n_{S C}} G_{d q N C(k, 2)} \\
& G_{d q S C 2}=G_{d q N C(2,5)}+G_{d q N C(5,5)}=\sum_{k=1}^{n_{S C}} G_{d q N C(k, 5)}
\end{aligned}
$$

$G_{d q S C 1}$ and $G_{d q S C 2}$ are the transfer functions for the first and the second healthy set, respectively. The $G_{d q(i, j)}$ are the $G$ elements from matrix $G_{d q N C}$ in (9) linking the $i^{\text {th }}$ input voltage to the $j^{\text {th }}$ output current.

In Fig. 3c, the frequency responses of the healthy modules under SC are compared against the frequency response of a module in NC. The difference between the nominal $\left(G_{v s d N C}\right)$ and two healthy sets $\left(G_{d q S C 1}\right.$ and $\left.G_{d q S C 2}\right)$ with the third one in SC is appreciated. The two transfer functions $G_{d q S C 1}$ and $G_{d q S C 2}$ can be used to design the current controllers for SC fault condition. As all the considerations are the same for the second module, only simulation results from the $q$-axis of the first module will be discussed.

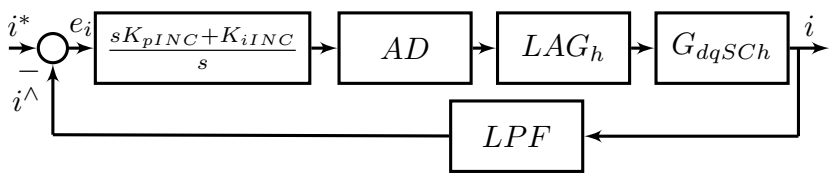

Fig. 7. Equivalent current control loop design in SC.

The different SC frequency responses are given by the interactions among different EMFs and current ripples from the circulating currents within the SC set of windings. The frequency response can be kept constant by adding a lag compensator to the current control loop. This is the main contribution of this work if compared to the previous control strategy presented in [7]. Fig. 7 illustrates the updated equivalent current control loop in SC, where the two plants are $G_{d q S C 1}$ and $G_{d q S C 2}$, from (16) and (17), respectively. $L A G_{h}$ denotes the lag compensator, where $h=1 \ldots N$ is the module index, which design will be detailed in the next paragraph. It is important to notice that by adding the lag compensators to the healthy current controllers, there is no need to update the PI parameters $\left(K_{p I S C}=K_{p I N C}\right.$ and $\left.K_{i I S C}=K_{i I N C}\right)$.

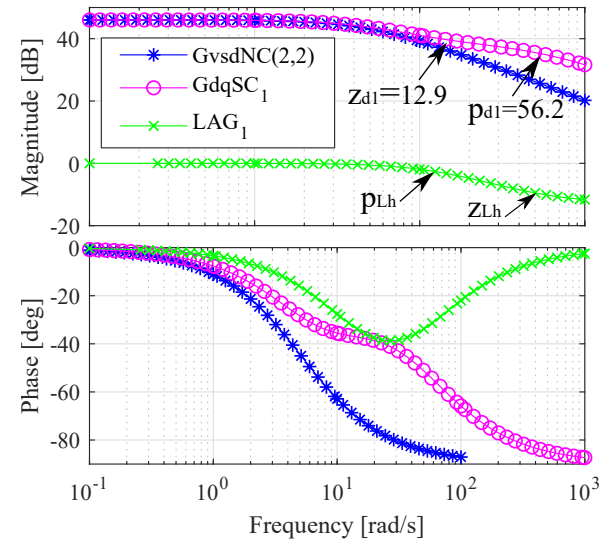

Fig. 8. Bode diagrams showing the lag compensator for the first module.

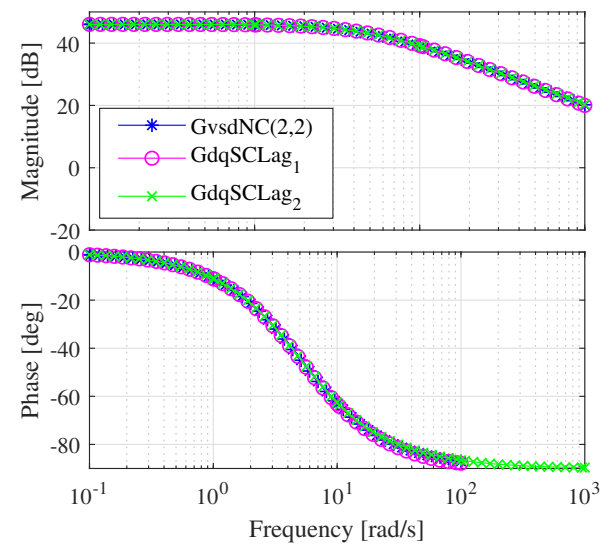

Fig. 9. The lag compensator designs for first and second module balance out the phase leading in SC.

In Eq. 18, the transfer function of a lag compensator is defined by $\tau_{L h}$ and $\alpha_{L h}$, as following:

$$
L A G_{h}(s)=\frac{1+\alpha_{L h} \tau_{L h} s}{1+\tau_{L h} s}
$$

The $L A G_{h}(s)$ is characterized by one pole $p_{L h}=-1 / \tau_{L h}$ and one zero $z_{L h}=-1 / \alpha_{L h} \tau_{L h}$. In order to compute the parameters of $\tau_{L h}$ and $\alpha_{L h}$ in Eq. (18), pole and zero of the complex $G_{d q S C}$ transfer function are identified initially based on the dominant pole-zero algorithm presented in [7], [20], [21]. In Fig. 8, the bode diagram of the lag compensator for the $q$-axis of the first module $\left(L A G_{1}\right)$ is shown together with the SC plant $\left(G_{d q S C_{1}}\right)$ and the $\mathrm{NC}$ transfer function $G_{v s d N C}(2,2)$. It can be observed from the bode plots that the dominant pole-zero of the plant are respectively denoted by $z_{d 1}$ and $p_{d 1}$. Hence, by designing $\tau_{L h}$ and $\alpha_{L h}$ on dominant pole-zero $\left(z_{d 1}\right.$ and $\left.p_{d 1}\right)$ with Eq. (19), dynamics of healthy modules can be restored to the nominal ones.

$$
\tau_{L h}=\frac{1}{z_{d 1}}, \alpha_{L h}=\frac{1}{p_{d 1} \tau_{L h}}
$$

By substituting the values from (19) into (18), the lag compensator design balances out the phase leading introduced by the SC fault condition. In Fig. 9, the equivalence between compensated plants in (20) and nominal plant $G_{v s d N C}(2,2)$ can be appreciated. Further analysis and comparison of output currents behaviour are discussed in next section.

$$
G_{d q S C L a g_{h}}(s)=L A G_{h}(s) G_{d q S C_{h}}(s)
$$




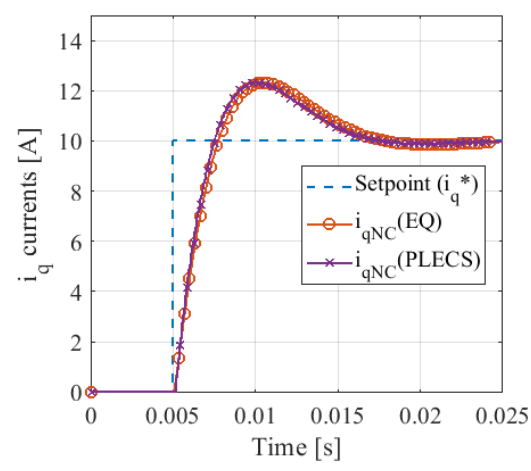

(a) Relationship between EQ and PLECS model in $\mathrm{NC}$

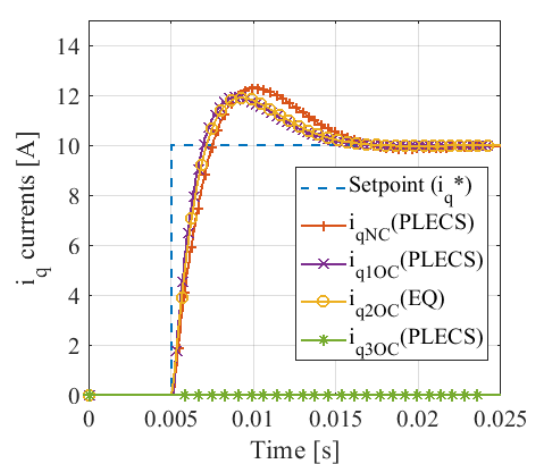

(b) With NUP PI gains in OC

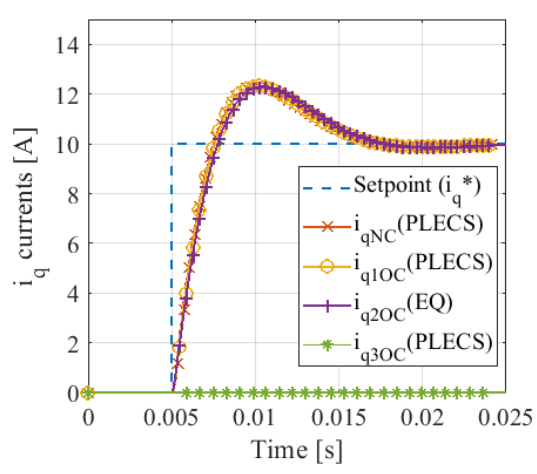

(c) With UP PI gains in OC, refer Table I

Fig. 10. Comparison between output current steps at locked rotor in nominal and open circuit condition.

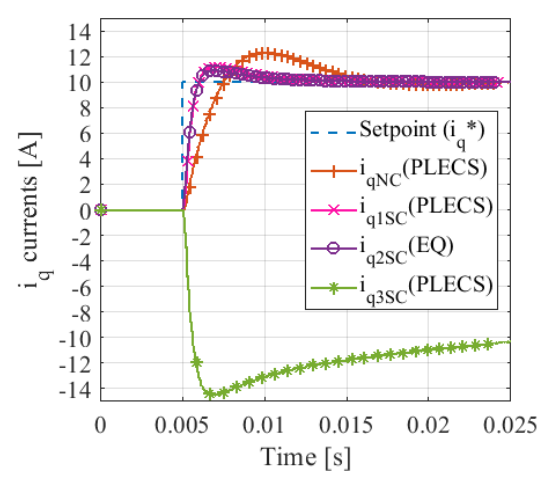

(a) With no Lag Compensators in SC

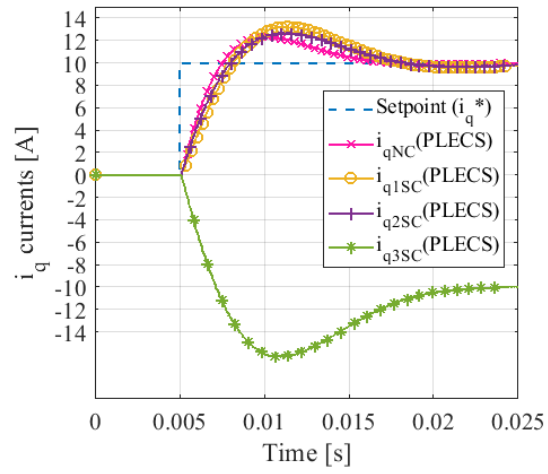

(b) With Lag Compensators in PLECS model SC



(c) With Lag Compensators in EQ model SC

Fig. 11. Comparison between output current steps at locked rotor in nominal and short circuit condition.

\section{Simulation Results}

The model developed in Sec. II is validated and compared based on the proposed current control strategy in all operating conditions; NC, OC, and SC by means of simulation in Matlab/Simulink and PLECS. The PLECS converter is feeding a custom voltage behind reactance model of a ninephase PMSM based on (1). Effects at high frequency are not going to be discussed in this paper for space constraint. In all simulations, the PI controllers are designed with the same input parameters (current bandwidth $\omega_{c}=600[\mathrm{rad} / \mathrm{s}]$ and phase margin $\left.\varphi_{c}=60^{\circ}\right)$. In the next sub-sec., it is highlighted that step responses in faulty conditions can be restored to the nominal ones by re-configuring the system as previously discussed in Sec. III, IV, and V. The main machine parameters used in the simulation are $r_{s}=0.005 \Omega$, interrupt time $T_{s}=0.0001 \mathrm{~s}$, current filter cut-off frequency $\omega_{f}=6.2832 \cdot 10^{5}[\mathrm{rad} / \mathrm{s}]$, and first harmonic inductance $d_{1 N C}=q_{1 N C}=9.763 \cdot 10^{-4}[\mathrm{rad} / \mathrm{s}]$. Since $d_{1 N C}=q_{1 N C}$, for brevity only $q$ current results are shown. The output currents are illustrated for first $\left(i_{q 1}\right)$ and second $\left(i_{q 2}\right)$ module with the last set of windings $\left(i_{q 3}\right)$ in $\mathrm{OC}$ or SC, relating the Simulink model (PLECS) used as a bench mark and the equivalent (EQ) model, where respectively denoted by $i_{q N C}(P L E C S)$ and $i_{q N C}(E Q)$.

\section{A. Nominal condition}

The simulated model in nominal condition is based on the current control loop introduced in Sec. III. Fig. 10a illustrates the output current steps for both EQ and PLECS model in nominal condition. It is evident that the two models have the equivalent response, which indicates the match between their $i_{q}$ output currents with the same PI parameters of $K_{p I N C}$ and $K_{i I N C}$.

\section{B. OC fault condition}

According to Fig. 6, the current dynamics in OC fault can be reconfigured by updating the PI gains $\left(K_{p I O C}\right.$ and $K_{\text {IIOC }}$ ) considering the OC harmonic inductance $q_{1 O C}=$ $6.829 \cdot 10^{-4}[H]$. Table I shows the updated PI gains in OC.

TABLE I

PI GAINS IN NOMINAL AND OC CONDITIONS

\begin{tabular}{|c|c|c|}
\hline PI gains & $K_{p I}$ & $K_{i I}$ \\
\hline $\mathrm{NC}$ & 0.858 & 379.362 \\
\hline OC & 0.599 & 266.679 \\
\hline
\end{tabular}

Fig. 10b shows the difference of output currents between NC $\left(i_{q N C}\right)$ and non-updating (NUP) the PI gains in OC for both PLECS $\left(i_{q 1 O C}(P L E C S)\right)$ and EQ $\left(i_{q 2 O C}(E Q)\right)$ model, while Fig. 10c shows the restored dynamics obtained by updating (UP) the PI gains. Based on the output currents transient, the match can be appreciated between UP PI gains from Table I of OC and healthy set in their PLECS and equivalent model. The PI gains in OC must be updated to tolerate with the fault and continue operate as in nominal 


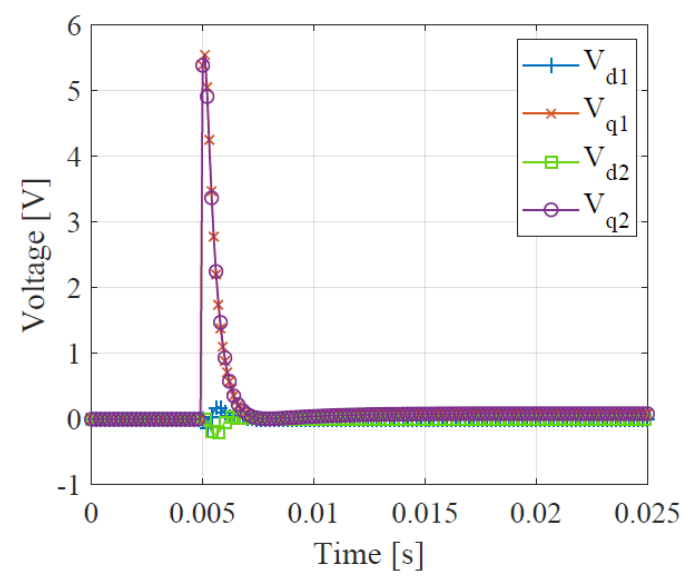

(a) With no Lag Compensators

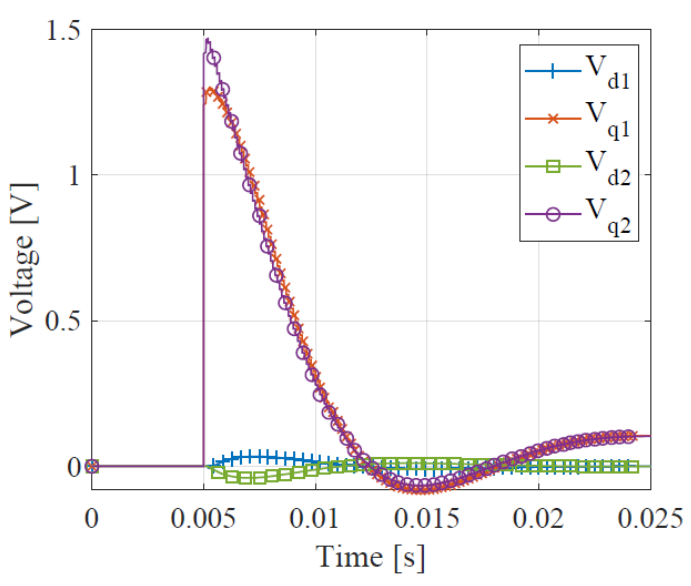

(b) With Lag Compensators

Fig. 12. $d q$ applied voltages at locked rotor with third module in short circuit.

condition, even in this particular case the current dynamics in OC is not heavily affected. Since the third set of the ninephase windings are in OC condition, therefore the $q$ currents $\left(i_{q 3 O C}\right)$ are all zero. As the rotor is locked, the Back Electro Motive Force (BEMF) voltages are zero and therefore not shown.

\section{SC fault condition}

The current dynamics control can be restored by introducing the lag compensator presented in Sec. V for the last set windings under SC fault. In Fig. 11, the comparison of output currents between SC and nominal condition in both PLECS and equivalent model are shown. Fig. 11a demonstrates the effects and difference between SC with no lag compensator and $\mathrm{NC}\left(i_{q N C}(P L E C S)\right)$ output currents, where $i_{q 1 S C}$ and $i_{q 2 S C}$ indicate the $q$ currents of first and second set of healthy modules under SC condition. It can be seen that the current dynamics is heavily affected without lag compensator. According to Fig. $11 \mathrm{~b}$ and $11 \mathrm{c}$, it is possible to appreciate the match between nominal and SC with lag compensator design for both PLECS and EQ model. The undesired SC effects are compensated by the lag compensator and it balances out phase leading introduced by the fault. Since the third set of three-phase is short-circuit, therefore the currents $i_{q 3 S C}$ shown are the circulating currents which approaching to zero value as the current control loop design is simulated in locked rotor position. On the other hand, this match is previously validated through the bode diagrams in Fig. 9, while the PI gains in SC current control loop are remain constant as applied in nominal $\left(K_{p I N C}, K_{i I N C}\right)$. In Fig. 12, both the $v_{d}$ and $v_{q}$ applied voltages from the first and second modules are shown. Whilst Fig. 12a presents the applied voltages without lag compensator, Fig. 12b shows the $d q$ voltages with the lag compensator. By looking at both the figures, a slower dynamics and a lower peak amplitude can be appreciated in Fig. $12 \mathrm{~b}$.

\section{CONCLUSION}

Post-fault control strategy is important to ensure the system can still deliver power after a fault while operating with the same high dynamic performance. This paper presents the distributed current control for Multi-Three-Phase machines and its compensation strategies for both OC and SC fault of one set of windings. The new PI parameters are analytically obtained for OC current control, and a lag compensator is designed in SC current control loop to eliminate the effects of the short circuit currents. The first harmonic inductance are obtained by diagonalising the state space model in $d q$ reference frame based on VSD technique. The overall VSD transformation is resulted from combining the two transformations which are geometrical and decoupling transformation. The advantage of this technique is that VSD theory can be developed only for the conventional multi-phase model instead of adapting VSD procedures on any particular multiphase winding topology that may occur in practice of phase arrangement of the actual machine. Finally, the proposed current control strategy in all three conditions; healthy, OC, and SC, were validated by means of Matlab/Simulink ${ }^{\circledR}$ simulations. The presented system appears to be a good candidate for multi-three phase applications where increased reliability and fault tolerance levels are required.

\section{REFERENCES}

[1] E. Levi, "Advances in converter control and innovative exploitation of additional degrees of freedom for multiphase machines," IEEE Transactions on Industrial Electronics, vol. 63, no. 1, pp. 433-448, Jan 2016.

[2] F. Barrero and M. J. Duran, "Recent advances in the design, modeling, and control of multiphase machines-part i," IEEE Transactions on Industrial Electronics, vol. 63, no. 1, pp. 449-458, Jan 2016.

[3] E. Levi, F. Barrero, and M. J. Duran, "Multiphase machines and drives - revisited," IEEE Transactions on Industrial Electronics, vol. 63, no. 1, pp. 429-432, Jan 2016.

[4] E. Levi, "Multiphase electric machines for variable-speed applications," IEEE Transactions on Industrial Electronics, vol. 55, no. 5, pp. 1893-1909, May 2008.

[5] E. Levi, R. Bojoi, F. Profumo, H. A. Toliyat, and S. Williamson, "Multiphase induction motor drives - a technology status review," IET Electric Power Applications, vol. 1, no. 4, pp. 489-516, July 2007.

[6] A. Galassini, A. Costabeber, M. Degano, C. Gerada, A. Tessarolo, and R. Menis, "Enhanced power sharing transient with droop controllers for multi-three-phase synchronous electrical machines," IEEE Transactions on Industrial Electronics, pp. 1-1, 2018.

[7] A. Galassini, A. Costabeber, M. Degano, C. Gerada, A. Tessarolo, and S. Castellan, "Distributed current control for multi-three phase synchronous machines in fault conditions," in 2016 XXII International Conference on Electrical Machines (ICEM), Sept 2016, pp. 10361042.

[8] M. Zabaleta, E. Levi, and M. Jones, "A novel synthetic loading method for multiple three-phase winding electric machines," IEEE Transactions on Energy Conversion, pp. 1-1, 2018.

[9] A. Galassini, A. Costabeber, and C. Gerada, "Speed control for multi-three phase synchronous electrical motors in fault condition," in IEEE EUROCON 2017 -17th International Conference on Smart Technologies, July 2017, pp. 698-703. 
[10] M. J. Duran and F. Barrero, "Recent advances in the design, modeling, and control of multiphase machines-part ii," IEEE Transactions on Industrial Electronics, vol. 63, no. 1, pp. 459-468, Jan 2016.

[11] L. Cheng, Y. Sui, P. Zheng, P. Wang, and F. Wu, "Implementation of postfault decoupling vector control and mitigation of current ripple for five-phase fault-tolerant pm machine under single-phase open-circuit fault," IEEE Transactions on Power Electronics, vol. 33, no. 10, pp. $8623-8636$, Oct 2018

[12] A. Mohammadpour and L. Parsa, "Post-fault control technique for multi-phase pm motor drives under short-circuit faults," in 2013 Twenty-Eighth Annual IEEE Applied Power Electronics Conference and Exposition (APEC), March 2013, pp. 817-822.

[13] W. N. W. A. Munim, H. S. Che, and W. P. Hew, "Fault tolerant capability of symmetrical multiphase machines under one open-circuit fault," in 4th IET Clean Energy and Technology Conference (CEAT 2016), Nov 2016, pp. 1-6.

[14] A. Mohammadpour, S. Sadeghi, and L. Parsa, "Fault-tolerant contro of five-phase pm machines with pentagon connection of stator windings under open-circuit faults," in 2012 Twenty-Seventh Annual IEEE Applied Power Electronics Conference and Exposition (APEC), Feb 2012, pp. 1667-1672.

[15] A. A. A. Hafez, R. Todd, A. J. Forsyth, and A. M. Cross, "Direct current ripple compensation for multi-phase fault-tolerant machines,' IET Electric Power Applications, vol. 5, no. 1, pp. 28-36, January 2011.

[16] A. Tani, M. Mengoni, L. Zarri, G. Serra, and D. Casadei, "Control of multiphase induction motors with an odd number of phases under open-circuit phase faults," IEEE Transactions on Power Electronics, vol. 27, no. 2, pp. 565-577, Feb 2012

[17] A. Mohammadpour and L. Parsa, "A unified fault-tolerant current control approach for five-phase pm motors with trapezoidal back emf under different stator winding connections," IEEE Transactions on Power Electronics, vol. 28, no. 7, pp. 3517-3527, July 2013.

[18] B. Tian, G. Mirzaeva, Q. An, L. Sun, and D. Semenov, "Fault-tolerant control of a five-phase permanent magnet synchronous motor for industry applications," IEEE Transactions on Industry Applications, vol. 54, no. 4, pp. 3943-3952, July 2018.

[19] Y. Hu, Z. Q. Zhu, and M. Odavic, "Comparison of two-individual current control and vector space decomposition control for dual threephase pmsm," IEEE Transactions on Industry Applications, vol. 53, no. 5, pp. 4483-4492, Sep. 2017.

[20] N. Martins, P. C. Pellanda, and J. Rommes, "Computation of transfer function dominant zeros with applications to oscillation damping control of large power systems," IEEE Transactions on Power Systems, vol. 22 , no. 4, pp. 1657-1664, Nov 2007.

[21] J. Rommes and N. Martins, "Efficient computation of multivariable transfer function dominant poles using subspace acceleration," IEEE Transactions on Power Systems, vol. 21, no. 4, pp. 1471-1483, Nov 2006.

\section{BIOGRAPHIES}

Azlia Abdul Rahman received the Master's degree in Mechatronics and Automatic Control Engineering in 2013 from the University Technology Malaysia. She is currently a Ph.D. student in Power Electronics, Machines and Control (PEMC) Research Group, at The University of Nottingham, U.K. Her research area is focused on control of multi-three phase machines.

Alessandro Galassini (S'13-M'17) received the Master's degree in Mechatronic Engineering in 2012 from the University of Modena and Reggio Emilia, Reggio Emilia, Italy. In 2017, he received the Ph.D. degree in power sharing for multithree-phase electrical machines from the University of Nottingham, Nottingham, U.K. Currently, he is a Researcher with the Power Electronics, Machines and Control (PEMC) Group, The University of Nottingham, Nottingham, U.K., and his research area is focused on control of electrical drives for future transportation systems.

Michele Degano (M'15) received the Laurea degree in electrical engineering from the University of Trieste, Trieste, Italy, in 2011, and the $\mathrm{Ph}$. degree in industrial engineering from the University of Padova, Padova, Italy, in 2015. In 2015, he joined the Power Electronics, Machines and Control (PEMC) Group, The University of Nottingham, Nottingham, U.K., as a Research Fellow, where he is currently an Assistant Professor teaching advanced courses on electrical machines. His main research interests include design and optimization of permanent-magnet machines, reluctance and permanent-magnet-assisted synchronous reluctance motors through genetic optimization techniques, for automotive and aerospace applications.

Haider Abbas Haider Abbas F. Almurib (S'00-M'05-SM'11) received the Ph.D. degree in electrical engineering from the University of Malaya, Kuala Lumpur, Malaysia, in 2006. He is currently a Professor with the Department of Electrical and Electronic Engineering, University of Nottingham Malaysia Campus, Semenyih, Malaysia, where he is also serving as the Head of the Department. He was a Senior Lecturer at the University of Malaya. He also worked in industry for four years as an Research and Development Engineer in the field of computer automation. His research interests include non-linear and intelligent control, electric machines and drives, embedded systems, and fault tolerance of digital systems. Prof. Almurib is an Associate Editor for IET Power Electronics.

Serhiy Bozkho Serhiy Bozhko (M'96-SM'18) received the M.Sc. and Ph.D. degrees in electromechanical systems from the National Technical University of Ukraine, Kyiv City, Ukraine, in 1987 and 1994, respectively. Since 2000, he has been with the Power Electronics, Machines and Controls Research Group, University of Nottingham, U.K., where currently he is a Professor of Aircraft Electric Power Systems. He is leading several EU- and industry-funded projects in the area of electric power systems for aerospace, including power generation, distribution, and conversion, power quality, control and stability issues, power management and optimization, as well as advanced modelling and simulations methods. 